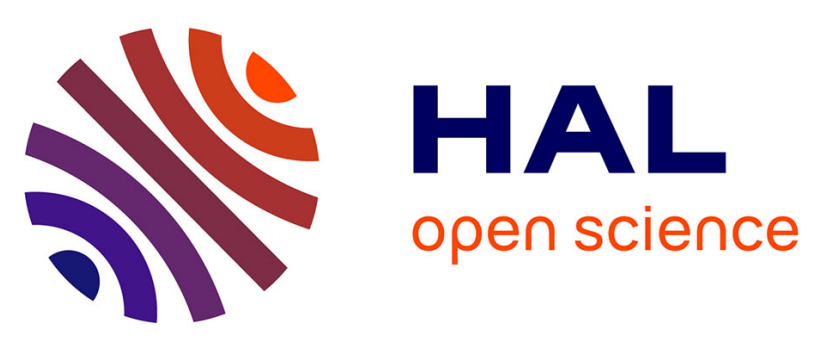

\title{
Test of SIMAGAZ: a LWIR cryogenic multispectral infrared camera for methane gas leak detection and quantification
}

\author{
Guillaume Druart, Pierre-Yves Foucher, Stéphanie Doz, Xavier Watremez, \\ Sophie Jourdan, Emmanuel Vanneau, Hadrien Pinot
}

\section{To cite this version:}

Guillaume Druart, Pierre-Yves Foucher, Stéphanie Doz, Xavier Watremez, Sophie Jourdan, et al.. Test of SIMAGAZ: a LWIR cryogenic multispectral infrared camera for methane gas leak detection and quantification. SPIE Defense + Commercial Sensing 2021, Apr 2021, Online, United States. pp.117270G, 10.1117/12.2586933 . hal-03213662

\section{HAL Id: hal-03213662 \\ https://hal.science/hal-03213662}

Submitted on 30 Apr 2021

HAL is a multi-disciplinary open access archive for the deposit and dissemination of scientific research documents, whether they are published or not. The documents may come from teaching and research institutions in France or abroad, or from public or private research centers.
L'archive ouverte pluridisciplinaire HAL, est destinée au dépôt et à la diffusion de documents scientifiques de niveau recherche, publiés ou non, émanant des établissements d'enseignement et de recherche français ou étrangers, des laboratoires publics ou privés. 


\title{
Test of SIMAGAZ: a LWIR cryogenic multispectral infrared camera for methane gas leak detection and quantification
}

\author{
Guillaume Druart*a, Pierre-Yves Foucher ${ }^{\mathrm{a}}$, Stéphanie Doz ${ }^{\mathrm{a}}$, Xavier Watremez ${ }^{\mathrm{b}}$, Sophie Jourdan ${ }^{\mathrm{c}}$, \\ Emmanuel Vanneau ${ }^{\mathrm{d}}$, Hadrien Pinot $^{\mathrm{e}}$ \\ aONERA, Chemin de la Hunière, 91761 Palaiseau Cedex, France; ${ }^{\mathrm{b}}$ TOTAL, Avenue Larribau, \\ 64018 Pau, France; ${ }^{\mathrm{C} L Y N R E D}$, route de Valence, 38113 Veurey-Voroise, France; ${ }^{\mathrm{d}}$ NOXANT, 24 \\ Avenue Emile Baudot, 91120 Palaiseau, France; ${ }^{e}$ BERTIN TECHNOLOGIES, 155 Rue Louis \\ Armand ZI, 13290 Aix-en-Provence, France \\ * Corresponding author: guillaume.druart@onera.fr
}

\begin{abstract}
Cryogenic cameras are an innovative alternative in the design of miniaturized infrared cameras using cryogenic detectors. In this presentation, we will apply this technology to design a snapshot multispectral camera for gas leak detection. A UAV compatible demonstrator in a commercial Detector Dewar Cooler Assembly (DDCA), called SIMAGAZ, has been made and tested in the TOTAL Anomaly Detection Initiatives (TADI) platform and the Esperse site of ONERA. The TADI infrastructure manages monitored gas leaks at flowrates from $0.1 \mathrm{~g} / \mathrm{s}$ to $300 \mathrm{~g} / \mathrm{s}$ and hosts remote sensors to test them in three scenarios: crisis-management, safety monitoring, and environmental monitoring. In Esperse site, first UAV flights with SIMAGAZ were performed. We demonstrate the ability to detect and quantify in real time the origin of methane gas leak, the flowrate and the volume of the plume with SIMAGAZ on ground or from a UAV. The core camera weights around $1 \mathrm{~kg}$, for around $1 \mathrm{~L}$ footprint and a power consumption of $10 \mathrm{~W}$ at the cooling steady state. Results from TADI and Esperse campaigns will be presented.
\end{abstract}

Keywords: Infared, Multispectral, Cryogenic camera, Methane, Detection, Quantification

\section{INTRODUCTION}

Methane leaks in petrochemical facilities present a risk to health and safety as well as a negative impact on environment. Major leak can potentially lead to explosive environments with a risk of major industrial accident. Existing gas leak detection systems mainly rely on point and path detection but these technologies require that the gas contacts physically the point sensor or moves between two path detectors. The drawback of these methods is that they don't permit to detect and localize early the small gas leak rates and to quantify any leak rates. Manual leak checks are also performed by monitoring one component at a time using a flame ionization detector or an optical gas imager but are time-consuming in regards with the complexity of the facilities. Moreover, with this method, the inspection is limited in time and small leaks may go undetected for extended period. Infrared gas cameras have thus become a key technology capable of visualizing gas plumes and are able to provide a continuous monitoring of large areas [1].

TOTAL is looking for a versatile remote sensing technology that can be applied in different ranges of methane leak flowrates in three main scenarios:

- Major leaks in crisis management with flowrate greater than $1 \mathrm{~kg} / \mathrm{s}$.

- Medium size leaks in safety monitoring with flowrate between $1 \mathrm{~g} / \mathrm{s}$ and $1 \mathrm{~kg} / \mathrm{s}$.

- Small leaks in environmental monitoring with flowrate smaller than $1 \mathrm{~g} / \mathrm{s}$.

Moreover the remote sensor should allow autonomous detection by replacing the operator with a computer vision algorithm. It should be able to detect and quantify in real time the origin of methane gas leak, the flowrate and the 
volume of the plume. Finally, the camera should be lightweight to be integrated in robots or drones for autonomous inspection.

Infrared cameras are able to detect methane gas since its absorption bands appear in the Mid-Wave InfraRed (MWIR) bandwidth around $3.2 \mu \mathrm{m}$ and in Long-Wave InfraRed (LWIR) bandwidth around 7.6 $\mu \mathrm{m}$. However state-of-art cameras and commercial cameras do not fully answer all the specifications of TOTAL. Some are monochromatic and thus sensitive to false alarms leading autonomous detection difficult. Indeed the methane plume can be difficult to distinguish by a computer vision algorithm from common interferences such as people, cars and steam. Other cameras are able to produce hyperspectral or multispectral images but the spectral content of the scene need to be scanned over time with a rotating filter wheel or moving mirrors. The frame rate is low and inadequate for mobile acquisition.

The FUI consortium IMAGAZ has developed SIMAGAZ, a camera for detection and quantification methane gas leak with the following specifications:

- Compact and lightweight to be integrated on a UAV

- With a high sensitivity to guarantee quick acquisition time

- Multispectral to quantify methane gas leak, to limit false alarm and to allow an autonomous detection with a computer vision algorithm.

To meet all these features, we took benefit of 10 years of R\&D between ONERA and LYNRED on cryogenic infrared cameras. Numerous works have shown the advantages of these cameras in terms of miniaturization Erreur ! Source du renvoi introuvable.-[5]. Moreover, by using a cryogenic infrared detector, we guarantee the high sensitivity of the camera.

SIMAGAZ is the pre-industrial version with a Technology Readiness Level (TRL) of 5 of a previous laboratory demonstrator studied in a project between ONERA and TOTAL called NAOMI (New Advanced Observation Method Integration).

\section{FEATURES OF SIMAGAZ}

The SIMAGAZ camera relies on the technology of cryogenic optics directly integrated in a standard Detector Dewar Cooler Assembly (DDCA). SIMAGAZ uses the LYNRED's state of the art architecture based on his cooled LW VGA format with a pixel pitch of $15 \mu \mathrm{m}$ and a RM3 cooler. So the outside view of the camera looks like a standard DDCA. Only the cold shield has been modified to integrate the optics. The optical part is simply made of a single array of lenses to produce 4 images of the scene on a single Focal Plane Array (FPA) and an array of filters to give the multispectral property of the camera, each filter being associated to a different optical channel. The MCT technology of the infrared detector array offers high speed operation with a high sensitivity. Indeed, a Noise Equivalent Temperature Difference (NETD) has a mean value of $40 \mathrm{mK}$ using bandpass filters with low FWHM and with an integration time of 5ms and for a scene at around $20^{\circ} \mathrm{C}$. Therefore, the camera combines the advantages of being simple (only two major optical components are used), cost effective (a single detection block is used), compact (the camera has the size of the detection block), sensitive (a cryogenic infrared detector is used), as well of having a high radiometric stability (the optics are at cryogenic temperature, thus limiting the background signal). The specifications of SIMAGAZ are summarized in Table 1. 
Table 1. Specifications of SIMAGAZ

\begin{tabular}{|c|c|}
\hline Detector type & MultiSpectral MCT \\
\hline Spectral Range & $7.2-8.5 \mu \mathrm{m}$ \\
\hline $\begin{array}{c}\text { Image Size for a sub- } \\
\text { image }\end{array}$ & $\begin{array}{c}320 \times 256 \text { pixels with a } \\
\text { pixel pitch of } 15 \mu \mathrm{m}\end{array}$ \\
\hline $\begin{array}{c}\text { Measurement Rate (with } \\
\text { image processing) }\end{array}$ & Up to $20 \mathrm{~Hz}$ \\
\hline $\begin{array}{c}\text { Volume of the core } \\
\text { camera }\end{array}$ & $1 \mathrm{~L}$ \\
\hline Weight of the core camera & $7 \mathrm{~mm}$ \\
\hline Focal length & 4 \\
\hline F-number & $40^{\circ}$ \\
\hline $\begin{array}{c}\text { Horizontal Field Of View } \\
\text { (HFOV) }\end{array}$ & Up to $20 \mathrm{~Hz}$ \\
\hline Measurement rate & $<0.5 \mathrm{~g} / \mathrm{s}$ \\
\hline $\begin{array}{c}\text { Sensitivity of methane } \\
\text { leak flowrates }\end{array}$ & \\
\hline
\end{tabular}

The core camera uses the processing unit for UAV airborne application of the NoxEngine technology platform from NOXANT. The NoxEngine combines innovative software architecture with specialized processors, so images can be acquired and processed in real-time, in a reduced footprint and energy consumption. A picture of the core camera is given in Figure 1.

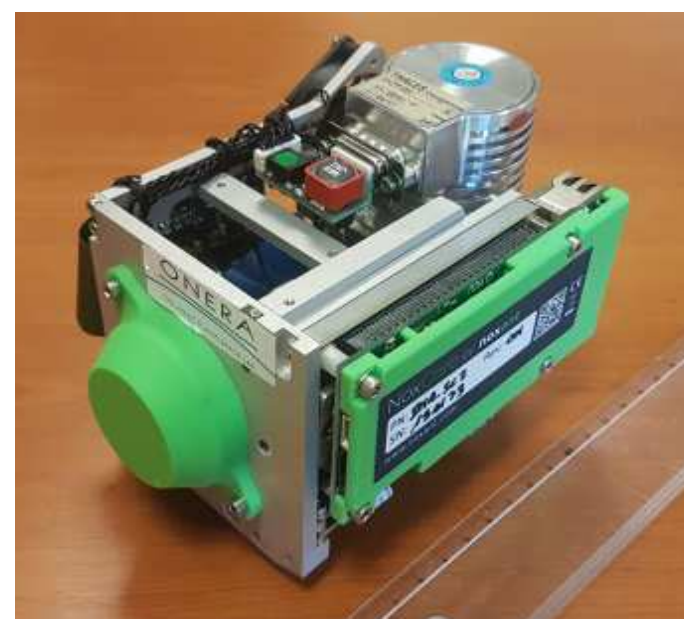

Figure 1. Core camera

A Human-Machine Interface (HMI) developed during the NAOMI project has been applied to SIMAGAZ to validate the ability to detect and quantify in real-time methane gas plumes.

\section{FIRST QUANTIFICATION RESULTS OF SIMAGAZ DURING TEST CAMPAIGNS}

The first results of SIMAGAZ were made on the TADI (TOTAL Anomaly Detection Initiatives) platform [6] in 2018. Total's Lacq Pilot Platform is a $2000 \mathrm{~m}^{2}$ test area for qualifying cost-effective systems designed to complement the gas 
detection system of a plant and provide valuable information should a gas leak incident occurs. New methodologies for the early detection of anomalies using remote observation systems including drones, robots and artificial intelligence data processing systems are currently being investigated there. The TADI infrastructure manages monitored gas leaks at flowrates from $0.1 \mathrm{~g} / \mathrm{s}$ to $300 \mathrm{~g} / \mathrm{s}$, making this site unique in the world. Anomaly scenarios can be reproduced in an industrial context. Indeed, as illustrated in Figure 2, a scrubber, a drum, a flare and a well head are present in this area where small gas leaks can be monitored. At the emission point, more important gas leaks can be monitored.

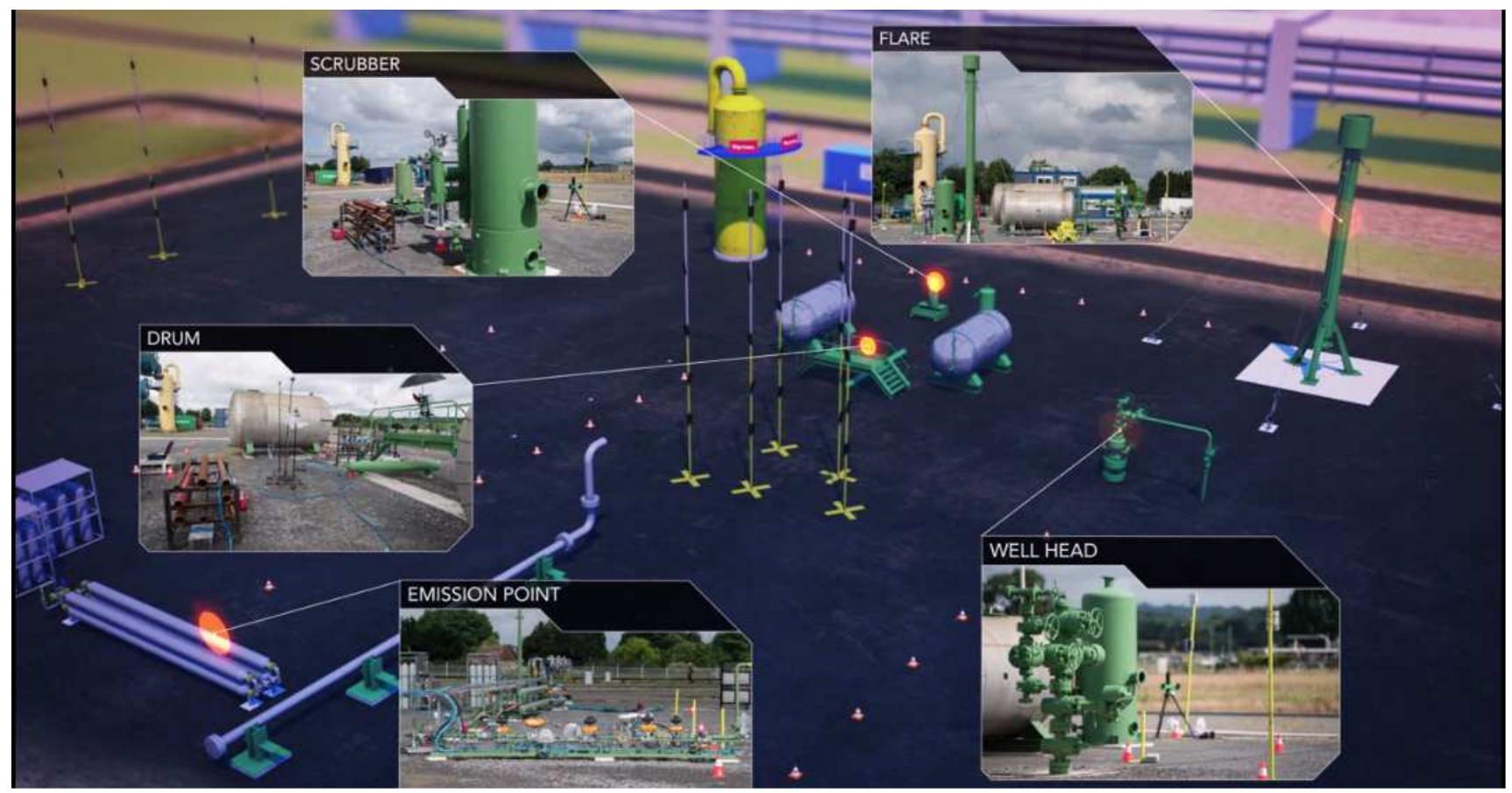

Figure 2. Illustration of the TADI platform. In the industrial context area, a scrubber, a drum, a flare and a well head are present where small gas leaks can be monitored. At the emission point, more important gas leaks can be monitored.

First SIMAGAZ was mounted on a 2-axis platinum turret as illustrated in Figure 3 and placed on a pod so that the camera can be elevated at $10 \mathrm{~m}$. SIMAGAZ monitored at a fixed position the test area at a distance of $80 \mathrm{~m}$.

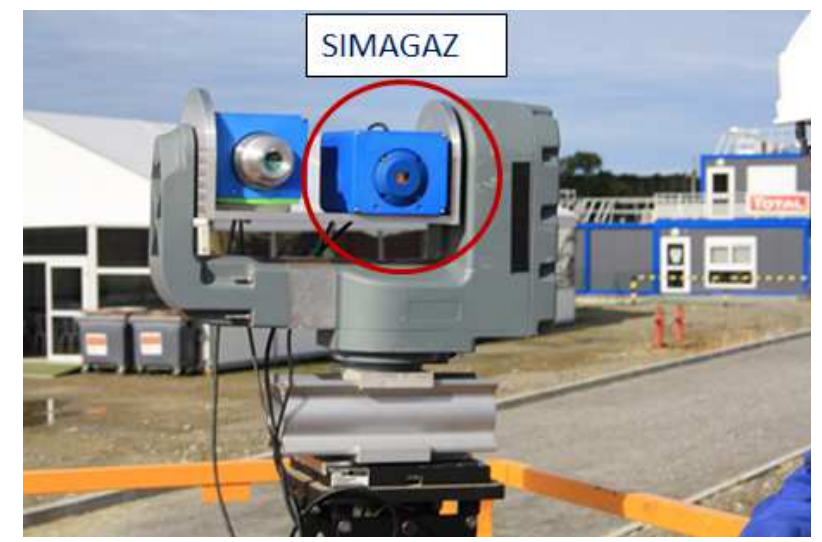

Figure 3. SIMAGAZ integrated on a turret 
Figure 4 shows some gas plume detection and quantification at different flowrates: $200 \mathrm{~g} / \mathrm{s}, 10 \mathrm{~g} / \mathrm{s}$ and $1 \mathrm{~g} / \mathrm{s}$ of methane. The quantification is given in false colour in ppm.m. Figure 4 illustrates the ability of SIMAGAZ to provide detection for large methane leak but also early leak detection of small leaks and even fugitive emissions, validating the three scenarios defined by TOTAL. For these tests, the quantification algorithms used a reference image without gas leak. That's why, the acquisition of the camera started just before the gas emission. The measured flowrates were consistent with the controlled flowrates.

(A)

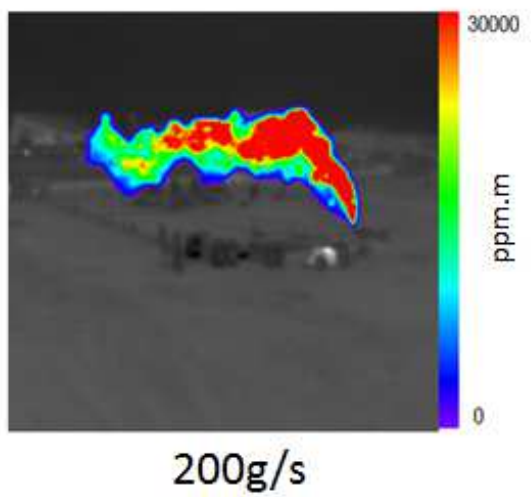

(B)

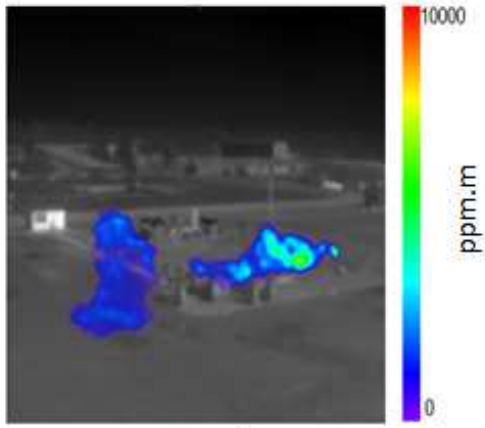

$10 \mathrm{~g} / \mathrm{s}$
(C)

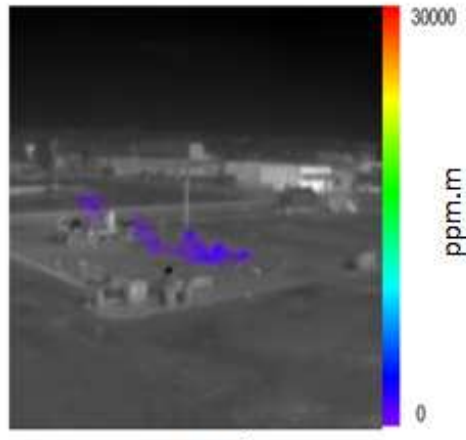

$1 \mathrm{~g} / \mathrm{s}$

Figure 4. Detection and quantification of methane gas plumes at different flowrates: A) 200g/s, B) 10g/s, C) 1g/s. SIMAGAZ monitored the test area at a distance of $80 \mathrm{~m}$.

Subsequently, SIMAGAZ was integrated in a small hexarotor UAV as illustrated in Figure 5. Test campaigns were first performed in Esperce site of ONERA and then in TADI platform. Figure 6 shows detection and quantification of small methane gas leak (under $1 \mathrm{~g} / \mathrm{s}$ ) from a gas cylinder in Esperce site using SIMAGAZ integrated on the small hexarotor UAV at different altitude heights. Figure 7 shows detection and quantification of methane gas leak in TADI platform. These detections are important results since we demonstrate that SIMAGAZ can perform a continuous monitoring on a mobile vehicle thanks to algorithms working image by image (without reference images).

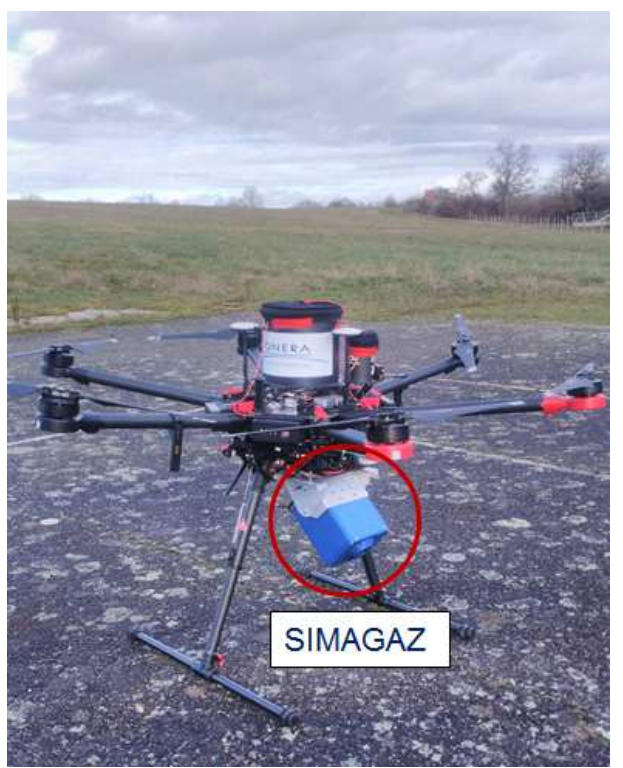

Figure 5. Integration of SIMAGAZ in a hexarotor UAV 

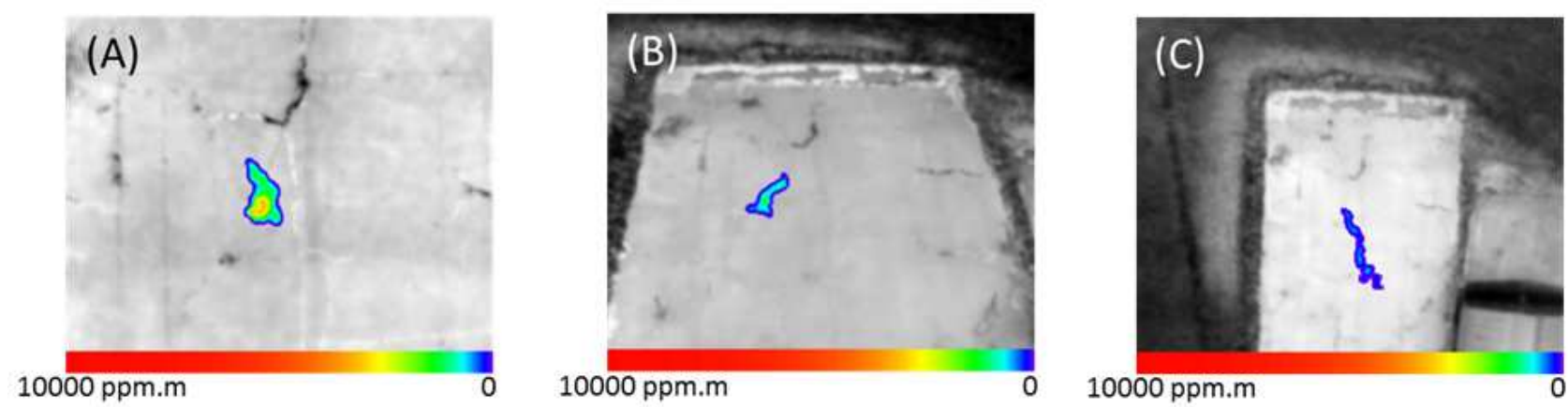

Figure 6. Detection and quantification of methane plumes from a UAV in Esperce site at different flight altitudes: A) nadir view angle at $20 \mathrm{~m}, 45^{\circ}$ view angle at $40 \mathrm{~m}$, nadir view angle at $60 \mathrm{~m}$.

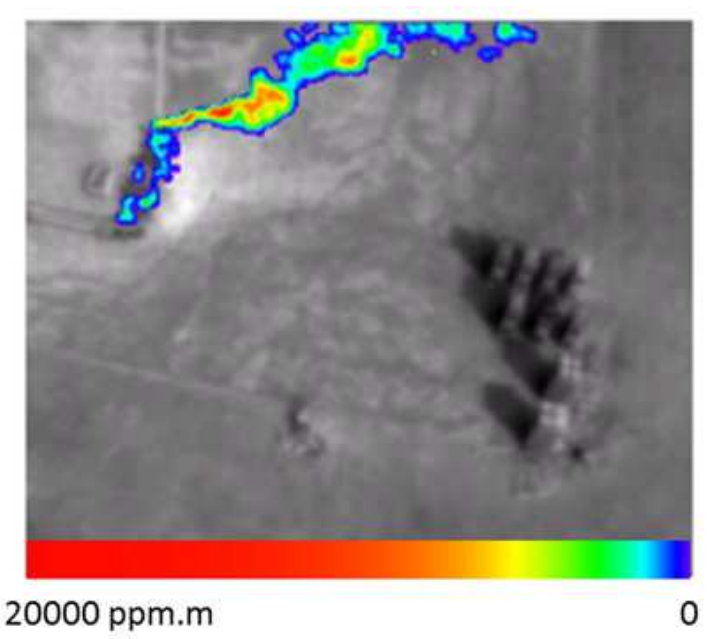

Figure 7. Detection and quantification of a methane plume from a UAV in TADI platform.

\section{CONCLUSION}

We demonstrate the ability of this four spectral LWIR camera on ground or on UAV, to detect in real time a methane gas leak with a quantification of its flow rate. In addition, the system allows an estimation of the volume of the plume and helps to investigate the origin of the leak. The core camera weights around $1 \mathrm{~kg}$ and has a footprint of around $1 \mathrm{~L}$ and power consumption at the cooling steady state of around 10W. Results from TADI and Esperce campaigns were presented. SIMAGAZ has proved its operability since it endured changing weather conditions without degradation of its radiometric performance. The quality of the images was stable in time and no additional calibrations were required during one-day test campaigns. The effectiveness of the quantification algorithms was provided through a co-design with the optical design that resulted in an optimal choice of filters and a cryogenic infrared camera with outstanding radiometric performances. SIMAGAZ validates the three scenarios considered by TOTAL: detection of large methane leaks, early leak detection of small leaks and fugitive emissions. In the following, three configurations of SIMAGAZ will be investigated: a fixed monitoring camera, a handheld camera for operators and a mobile camera integrated in an autonomous system. 


\section{REFERENCES}

[1] Abdel-Moati, H.M. 2014. Advanced Techniques for Autonomous Detection of Gas Releases. Presented at the SPE Middle East Health, Safety, Environment \& Sustainable Development Conference, 22-24 September, Doha, Qatar, SPE-170377-MS

[2] Michael Singer, Dov Oster, "Design of a cryogenic IR detector with integrated optics," Proc. SPIE 7660, Infrared Technology and Applications XXXVI, 76601Z (3 May 2010)

[3] R. C. Gibbons, S. H. Black, and R. N. Mullins, "System and method for viewing an area using an optical system positioned inside of a dewar," U. S. Patent 8,294,103 (23 October 2012)

[4] Guillaume Druart, Florence de la Barriere, Nicolas Guérineau, Joel Deschamps, Manuel Fendler, Nicolas Lhermet, Jacques Rulliere, Serge Magli, Yann Reibel, Jean-Baptiste Moullec, "Towards infrared DDCA with an imaging function," Proc. SPIE 8012, Infrared Technology and Applications XXXVII, 801228 (20 May 2011)

[5] Florence de la Barrière, Guillaume Druart, Nicolas Guérineau, Frédéric Champagnat, Aurélien Plyer, Gilles Lasfargues, and Serge Magli, "Compact multichannel infrared camera integrated in an operational detector dewar cooler assembly," Appl. Opt. 57, 4761-4770 (2018)

[6] Watremez, X. 2018. Remote sensing Technologies for Detecting, Visualizing and Quantifying Gas Leaks. Presented at the SPE International Conference on Health, Safety, Security, Environment, and Social Responsibility, 16-18 April, Abu Dhabi, UAE. SPE-190496-MS 